\section{Cureus}

Received 06/29/2018

Review began 07/02/2018

Review ended 07/03/2018

Published 07/06/2018

\section{C) Copyright 2018}

Lake et al. This is an open access article distributed under the terms of the Creative Commons Attribution License CC-BY 3.0., which permits unrestricted use, distribution, and reproduction in any medium, provided the original author and source are credited.

\title{
A Case Report of an Enlarged Suboccipital Nerve with Cutaneous Branch
}

\author{
Sasha Lake ${ }^{1}$, Joe Iwanaga ${ }^{2}$, Rod J. Oskouian ${ }^{3}$, Marios Loukas ${ }^{4}$, R. Shane Tubbs ${ }^{5}$ \\ 1. Anatomical Studies, St. George's, St. George, GRD 2. Medical Education and Simulation, Seattle Science \\ Foundation, Seattle, USA 3. Neurosurgery, Swedish Neuroscience Institute, Seattle, USA 4. Anatomical \\ Sciences, St. George's University, St. George, GRD 5. Neurosurgery, Seattle Science Foundation, Seattle, \\ USA
}

$\square$ Corresponding author: Joe Iwanaga, joei@seattlesciencefoundation.org Disclosures can be found in Additional Information at the end of the article

\section{Abstract}

Variations of the suboccipital nerve are infrequently reported. This nerve derived from the C1 spinal nerve is usually a small branch that primarily innervates the short suboccipital muscles. During the routine dissection of the occipital region in an adult cadaver, a vastly enlarged leftsided suboccipital nerve was identified. The nerve innervated the short suboccipital muscles and overlying semispinalis capitis in normal fashion. However, it continued cranially to end in the overlying skin of the occiput. Although not normally thought to have a cutaneous branch, recalcitrant occipital neuralgia might be due to such a variant branch. Future studies are necessary to further elucidate this proposed pathomechanism.

Categories: Neurology, Pathology

Keywords: suboccipital nerve, c1 nerve, occiput cutaneous innervation, sensory suboccipital nerve

\section{Introduction}

The suboccipital nerve is the dorsal ramus of $\mathrm{C} 1$. This nerve is found between the skull and atlas and within the suboccipital triangle. Here, it is positioned between the posterior arch of the atlas and vertebral artery bordering the nerve inferiorly and superiorly, respectively [1]. The suboccipital nerve innervates the rectus capitis posterior major and minor, obliquus capitis superior, obliquus capitis inferior, and semispinalis capitis.

A spinal nerve's dorsal root and dorsal ganglion carry sensory fibers to the spinal cord. Interestingly, a dorsal root ganglion for $\mathrm{C} 1$ has been reported to be found in less than $10 \%$ of dissections [2]. However, on a microscopic level, collections of sensory neurons have been identified along the accessory nerve in embryos and adult human cadavers with some positing that these represent cells of the dorsal root ganglion of $\mathrm{C} 1$. Neuronal collections have also been visualized grossly along the accessory nerve [2]. Moreover, from a gross perspective the dorsal root ganglion may not be identified grossly even when the dorsal root is present [3], but ectopic neurons can be microscopically seen [4]. The function of the suboccipital nerve is understood to be primarily motor, and not surprisingly, the $\mathrm{C} 1$ ventral root is larger compared to its dorsal root - a characteristic that is unique to this nerve compared to other spinal nerves [3]. Taken together, the sensory innervation of the suboccipital nerve is not well understood [3].

\section{Case Presentation}

During the routine dissection of the occipital region in an adult cadaver, a vastly (approximately four times the size of the contralateral suboccipital nerve) enlarged left-sided suboccipital nerve was identified (Figures 1, 2). The suboccipital nerve on the left side coursed just medial to the 


\section{Cureus}

vertebral artery at the posterior arch of the atlas. The nerve innervated the short suboccipital muscles and overlying semispinalis capitis in normal fashion. However, it continued cranially to end in the overlying skin of the occiput by piercing the overlying trapezius muscle. The patch of skin was located below the lambdoid suture at the level of the inion (Figure 1). No articular branches were identified arising from the suboccipital nerve. The right-sided suboccipital nerve was found to have a typical size and length and did not have a cutaneous branch. No other regional anatomical variations or pathology were identified.

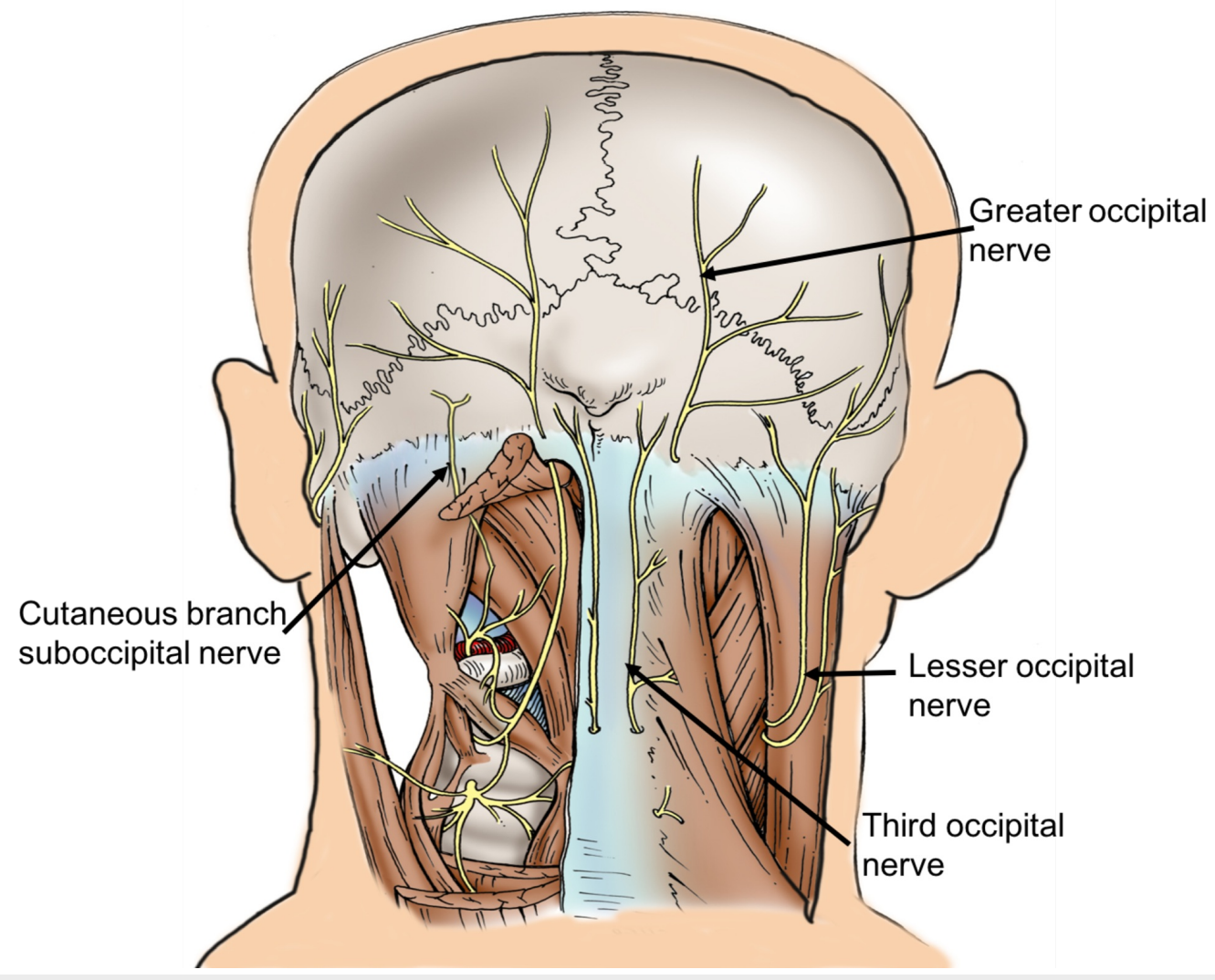

FIGURE 1: Schematic drawing of the specimen reported herein.

Note the variant cutaneous branch of the suboccipital nerve on the left side. 


\section{Cureus}

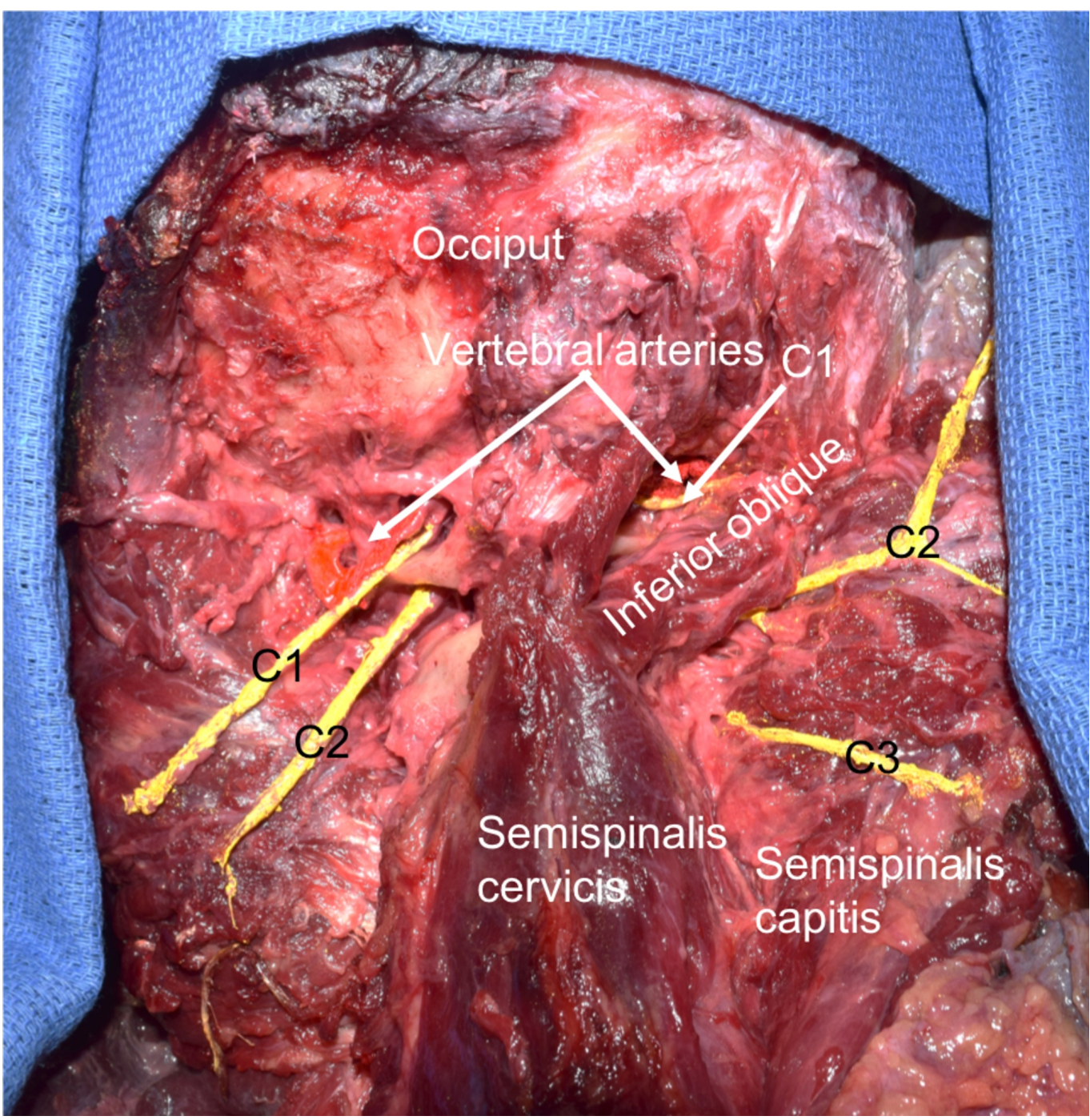

\section{FIGURE 2: Cadaveric specimen with dissection of the suboccipital region.}

Note the large and long dorsal ramus of $\mathrm{C} 1$ on the left and compare this to the size of the normal dorsal ramus of $\mathrm{C} 1$ on the right side. For reference, the semispinalis capitis muscle is reflected laterally on both sides. Also observe the relationship of the suboccipital nerves and the vertebral arteries as they course over the posterior arch of the atlas.

\section{Discussion}

The accessory nerve and C1 can be found to have anastomoses. Type I is described as a formation of $\mathrm{C} 1$ spinal nerve from ventral roots, but lacking dorsal roots and having an anastomosis with the accessory nerve. Typical formation of spinal nerves, where the nerve is formed by both dorsal and ventral roots, represents a type II neural interconnection without an anastomosis between $\mathrm{C} 1$ and the accessory nerve. Type III describes a nerve (Mackenzie's nerve) connecting the C1 nerve to the accessory nerve. Under type III classification, the suboccipital nerve also has typical spinal nerve formation. Lastly, type IV represents a C1 nerve that lacks dorsal rootlets with anastomotic connection with the accessory nerve and ventral roots of $\mathrm{C} 1$ nerve, via Mackenzie's nerve.

On a microscopic level, collections of sensory neurons of the $\mathrm{C} 1$ nerve have been consistently localized coursing along the accessory nerve in embryos and adult human cadavers. These 
neuronal collections can also be appreciated grossly along the accessory nerve. The ganglia have been theorized to be involved in muscle spindle fiber proprioception but not cutaneous innervation [4].

Although not normally thought to have a cutaneous branch, recalcitrant occipital neuralgia might be due to such a variant branch of the suboccipital nerve as reported herein $[5,6]$. Additionally, studies aimed at tracing these cutaneous pathways when a C1 dorsal ganglion or root does not exist will add to our knowledge of this spinal nerves' frequent connections to the accessory nerve [7,8]. Additionally, with improved imaging of the neck muscles, newer technologies might better illustrate the nerves of this area [9]. Although Bergman et al. [10] have mentioned that this nerve "occasionally supplies a cutaneous branch to the back of the head," further anatomical studies are needed to quantitate this variation and help precisely localize the skin innervated by the nerve.

\section{Conclusions}

Future studies are necessary to further elucidate the anatomy of a cutaneous branch of the suboccipital nerve including its prevalence. Until then, clinicians who treat patients with occipital pain might consider the possibility of a cutaneous contribution to this area from the suboccipital nerve.

\section{Additional Information}

\section{Disclosures}

Human subjects: Consent was obtained by all participants in this study. Conflicts of interest: In compliance with the ICMJE uniform disclosure form, all authors declare the following:

Payment/services info: All authors have declared that no financial support was received from any organization for the submitted work. Financial relationships: All authors have declared that they have no financial relationships at present or within the previous three years with any organizations that might have an interest in the submitted work. Other relationships: All authors have declared that there are no other relationships or activities that could appear to have influenced the submitted work.

\section{References}

1. Payne R: Surgical exposure of the nerves of the back. Nerves and Nerve Injuries. Elsevier Limited, 2015. 2:155-167. 10.1016/B978-0-12-802653-3.00060-9

2. Gray H, Williams PL, Bannister LH: Gray's Anatomy: The Anatomical Basis of Medicine and Surgery. Churchill Livingstone, New York; 1995.

3. Tubbs RS, Loukas M, Slappey JB, Shoja MM, Oakes WJ, Salter E: Clinical anatomy of the C1 dorsal root, ganglion and ramus: a review and anatomical study. Clin Anat. 2007, 20:624-627. 10.1002/ca.20472

4. Hovorka MS, Uray MJ: Microscopic clusters of sensory neurons in C1 spinal nerve roots and in the C1 level of the spinal accessory nerve in adult humans. Anat Rec. 2013, 296:1588-1593. 10.1002/ar.22757

5. Cesmebasi A, Muhleman MA, Hulsberg P, Gielecki J, Matusz P, Tubbs RS, Loukas M: Occipital neuralgia: anatomic considerations. Clin Anat. 2015, 28:101-108. 10.1002/ca.22468

6. Watanabe K, Saga T, Iwanaga J, Tabira Y, Yamaki KI: An anatomical study of the transversus nuchae muscle: application to better understanding occipital neuralgia. Clin Anat. 2017, 30:3238. 10.1002/ca.22797

7. Cesmebasi A, Spinner RJ: An anatomic-based approach to the iatrogenic spinal accessory nerve injury in the posterior cervical triangle: how to avoid and treat it. Clin Anat. 2015, 28:761-766. 10.1002/ca.22555

8. Restrepo CE, Tubbs RS, Spinner RJ: Expanding what is known of the anatomy of the spinal accessory nerve. Clin Anat. 2015, 28:467-471. 10.1002/ca.22492

9. Au J, Perriman DM, Pickering MR, Buirski G, Smith PN, Webb AL: Magnetic resonance imaging 


\section{Cureus}

atlas of the cervical spine musculature. Clin Anat. 2016, 29:643-659. 10.1002/ca.22731

10. Illustrated encyclopedia of human anatomic variation. (2018). Accessed: June 25, 2018:

http://www.anatomyatlases.org/AnatomicVariants/NervousSystem/Text/FirstCervicalNerve.shtml 